\title{
THE
}

\section{Improving forecasting for telemarketing centers by ARIMA modeling with intervention}

\author{
Lisa Bianchi \\ University of Rhode Island \\ Jeffrey E. Jarrett \\ University of Rhode Island, jejarrett133@outlook.com \\ R. Choudary Hanumara
}

Follow this and additional works at: https://digitalcommons.uri.edu/cba_facpubs

Terms of Use

All rights reserved under copyright.

\section{Citation/Publisher Attribution}

Lisa Bianchi, Jeffrey Jarrett, and R. Choudary Hanumara. 1998. "Improving forecasting for telemarketing centers by ARIMA modeling with intervention. International Journal of Forecasting 14, no. 4 (December 1998): 497-504. https://doi.org/10.1016/S0169-2070(98)00037-5

Available at: https://doi.org/10.1016/S0169-2070(98)00037-5

This Article is brought to you for free and open access by the College of Business at DigitalCommons@URI. It has been accepted for inclusion in College of Business Faculty Publications by an authorized administrator of DigitalCommons@URI. For more information, please contact digitalcommons-group@uri.edu. 


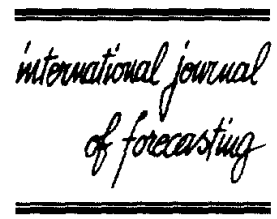

\title{
Improving forecasting for telemarketing centers by ARIMA modeling with intervention
}

\author{
Lisa Bianchi, Jeffrey Jarrett*, R. Choudary Hanumara \\ The New England Epidemiological Institute, Newton, MA, USA \\ University of Rhode Island, Kingston, RI, USA
}

\begin{abstract}
In this study we analyze existing and improved methods for forecasting incoming calls to telemarketing centers for the purposes of planning and budgeting. We analyze the use of additive and multiplicative versions of Holt-Winters (HW) exponentially weighted moving average models and compare it to Box-Jenkins (ARIMA) modeling with intervention analysis. We determine the forecasting accuracy of HW and ARIMA models for samples of telemarketing data. Although there is much evidence in recent literature that "simple models" such as Holt-Winters perform as well as or better than more complex models, we find that ARIMA models with intervention analysis perform better for the time series studied. (C) 1998 Elsevier Science B.V. All rights reserved.
\end{abstract}

Keywords: Holt-Winters models; Intervention Analysis; Box-Jenkins (ARIMA) modeling; Time Series

\section{Introduction}

In this study we examine forecasting of incoming calls to telemarketing centers. These centers are responsible for answering incoming requests from customers who desire immediate attention. Customers placed on hold in a buying or information gathering session are less satisfied, making the forecasting of demand for telemarketing services extremely important. Accurate and timely forecasting is essential and telemarketing centers have primarily used simple models. The NAMES system developed by AT\&T has used simple models for this purpose in the past.

Past studies have often compared simpler to more sophisticated methods using "M competition" data

\footnotetext{
${ }^{*}$ Corresponding author.
}

and have concluded that simple methods predict as well as the more complex methods (Makridakis et al., 1982 and Thompson, 1981). Other studies provide evidence as to the usefulness of Holt-Winters multiplicative forecasting model for predicting items such as inventory and stock levels, revenues, demand, and earnings per share whenever the time series data have shown the property of seasonality. Holt-Winters (HW) model (Holt, 1957; Winters, 1960 ) is an extrapolative technique that isolates the level, trend, and seasonal components of a time series regardless of the nature of the time series data being collected. It provides a cost-effective alternative to more sophisticated methods such as ARIMA modeling of the Box-Jenkins variety. Furthermore, it is more cost efficient and effective than using so-called "expert opinion" in most cases. (See Brandon and Jarrett, 1979, and Brandon et al., 1986). 
Others have indicated that there are problems with error analysis of HW models (McKenzie, 1986) and providing prediction intervals for these same models (Chatfield and Yar, 1990, and Chatfield and Yar, 1991). These last three studies were designed to study the variance of errors of the ARIMA structure and the prediction intervals for the HW model.

AT\&T Bell Laboratories used the HW forecasting model during the period of this study with its telemarketing scheduling system (i.e., NAMES Scheduling System). This system produces forecasts of daily incoming-call volumes to twenty centers in the United States. These telemarketing centers are responsible for answering customers' inquiries regarding phone service billings and the ordering, changing, and cancellation of phone services, and are open seven days a week. No data were kept on the types of calls but they did indicate that there is some variation associated with the day of the week. The NAMES system permits the forecaster to choose between the additive and multiplicative HW models but does not have any automatic method for choosing which is better for a particular time series.

The HW multiplicative model is given by,

$$
Y(t)=(a(t)+b) s(t)+e(t) .
$$

This equation contains a local linear trend, $(a(t)+b)$, a multiplicative seasonal factor, $s(t)$, and a random error term, $e(t)$. The seasonal component, $s(t)$, is used to represent patterns in the data which repeat every week. Thus, the current seasonal variation is defined as the current observation divided by the current mean level of the series.

The NAMES ${ }^{\text {TM }}$ system, as noted before, contains the additive HW model. Additive seasonal factors are appropriate when seasonal variation is constant over time. The additive model is given by,

$$
Y(t)=(a(t)+b)+s(t)+e(t) .
$$

This model contains an additive seasonal factor, $s(t)$, and a random error term, $e(t)$. The three components are defined as they were in the multiplicative case. We should note that the NAMES system uses an adaptive approach to find the optimal values for trend and seasonality.

Previously, Grambsch and Stahel (1990) estab- lished that more sophisticated ARIMA models are better at forecasting the demand for special telephone services. The study indicated the benefits of ARIMA modeling when dealing with a large number of time series of telephone services and how it compares with other fitting techniques.

We propose to analyze the usefulness of HW models and compare them with fitting enhanced ARIMA models. Pack (1990) indicated that forecasters could go beyond the basic univariate model by considering interventions and other real aspects of observed time series. In addition, others (Brandon et al., 1983, and Mahmoud, 1984) observed this phenomenon in studying a large number of real financial time series. One of their conclusions was that univariate ARIMA modeling, while useful, could still be improved. For a general discussion of ARIMA models, we refer one to a standard text on Box-Jenkins time series modeling (Bowerman and O'Connell, 1993, and Jarrett, 1991).

\section{The study}

In this study we evaluate the current use of the Holt-Winters' model for forecasting as done by NAMES system and indicate whether improvement is possible and desirable through use of ARIMA time series modeling. The system is important because of its' wide use by AT\&T during the period of this study. Its' obvious advantage was that it was simple to operate; required a minimal amount of knowledge on the part of the forecaster; and that it was developed particularly to solve the problem of planning for telemarketing centers.

The alternative model chosen were ARIMA models with an adjustment (intervention analysis) to correct for outliers. No ad hoc outlier handling system could have been included in the HW models handled under the NAMES system.

The data analyzed consist of daily call volumes from March 1, 1991 to June 26, 1991, placed in each of 117 area codes in the United States. A proportional stratified random sampling plan was utilized to determine the area codes that were examined. The time zones Eastern, Central, Mountain, and Pacific (including Hawaii) determine the strata, and these 
Table 1

Area codes and time zones

\begin{tabular}{ll}
\hline Time zone & Number of area codes \\
\hline Eastern & 51 \\
Central & 41 \\
Mountain & 9 \\
Pacific & 16 \\
\hline
\end{tabular}

time zones were utilized to ensure that area codes from varying parts of the nation were examined. Table 1 below indicates the time zone and the number of area codes in them. A total of six or $5 \%$ of the 117 area codes were studied. The area codes that were randomly chosen were 201 (New Jersey), and 614 (Ohio) from the Eastern Time Zone; 314 (Missouri) and 504 (Louisiana) from the Central Time Zone; 303 (Colorado) from the Mountain Time Zone; and 808 (Hawaii) from the Pacific Time Zone. Initial plots of the data revealed weekly seasonality, the existence of outliers, and no apparent trend in the data over time. As an example, the day to day behavior of call volumes within area code 201 (Fig. 1) contains two observable outliers; one on March 14, 1991 and the other on May 6, 1991. The methods used to determine outliers will be discussed later. Note also, there is a pattern during the week with Monday having the largest number of calls and Sundays the least number of calls. Close inspections of the data reveal other days that may be considered outliers. Figs. 2-4 are time series plots of the daily call volumes for several days of the week for the same area code. Often, but not always, the outliers appear on or near holidays, e.g., Mother's Day.

\section{The forecasting models}

Management used forecasts to produce work schedules one week in advance. Since BJ modeling requires a substantial amount of data for the identification and estimation processes, the first 49 observations (March 1, 1991 through April 18, 1991) were

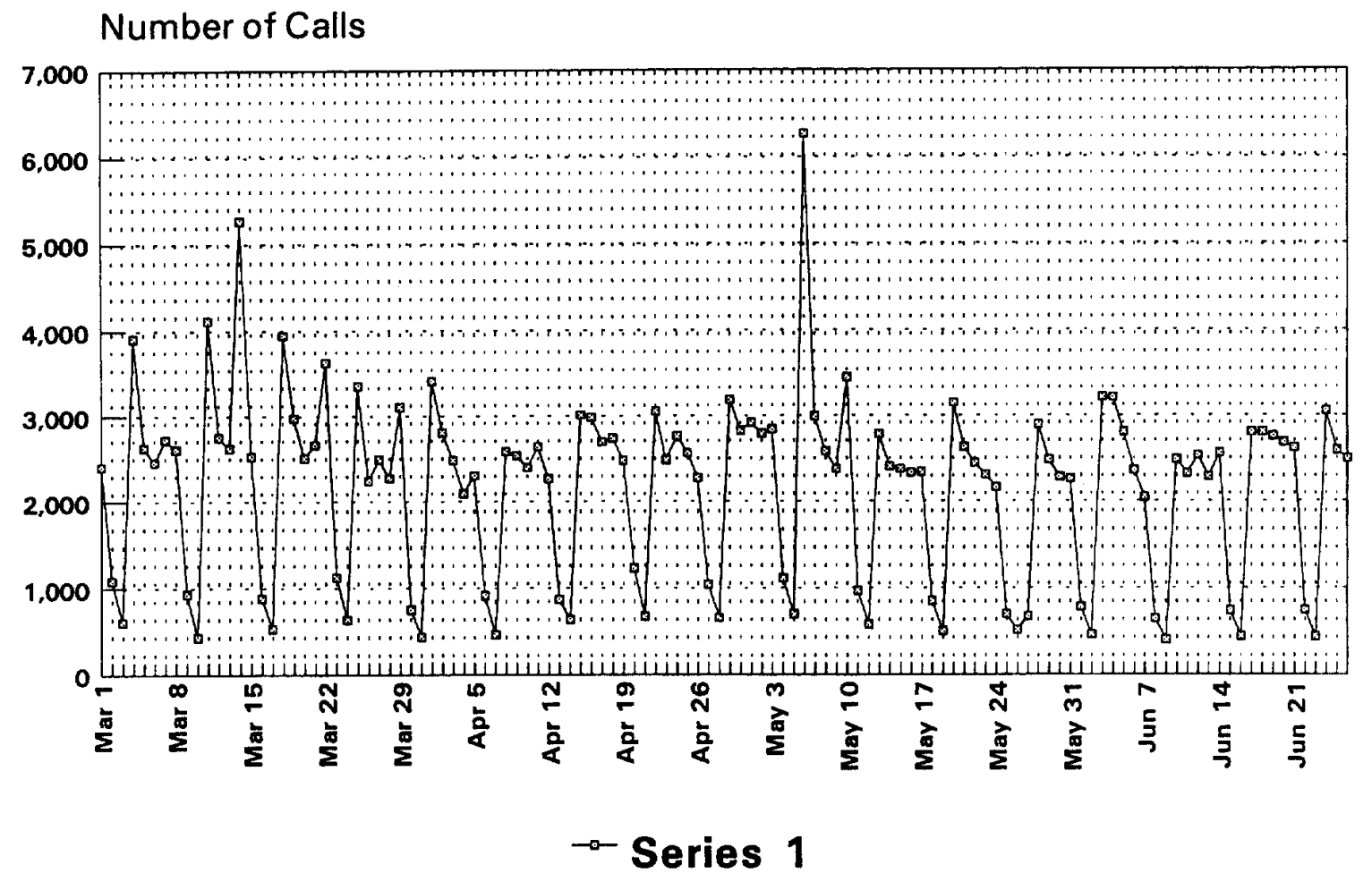

Fig. 1. Time plot of daily call volumes, Area code 201 . 


\section{Number of Calls (Thousands)}

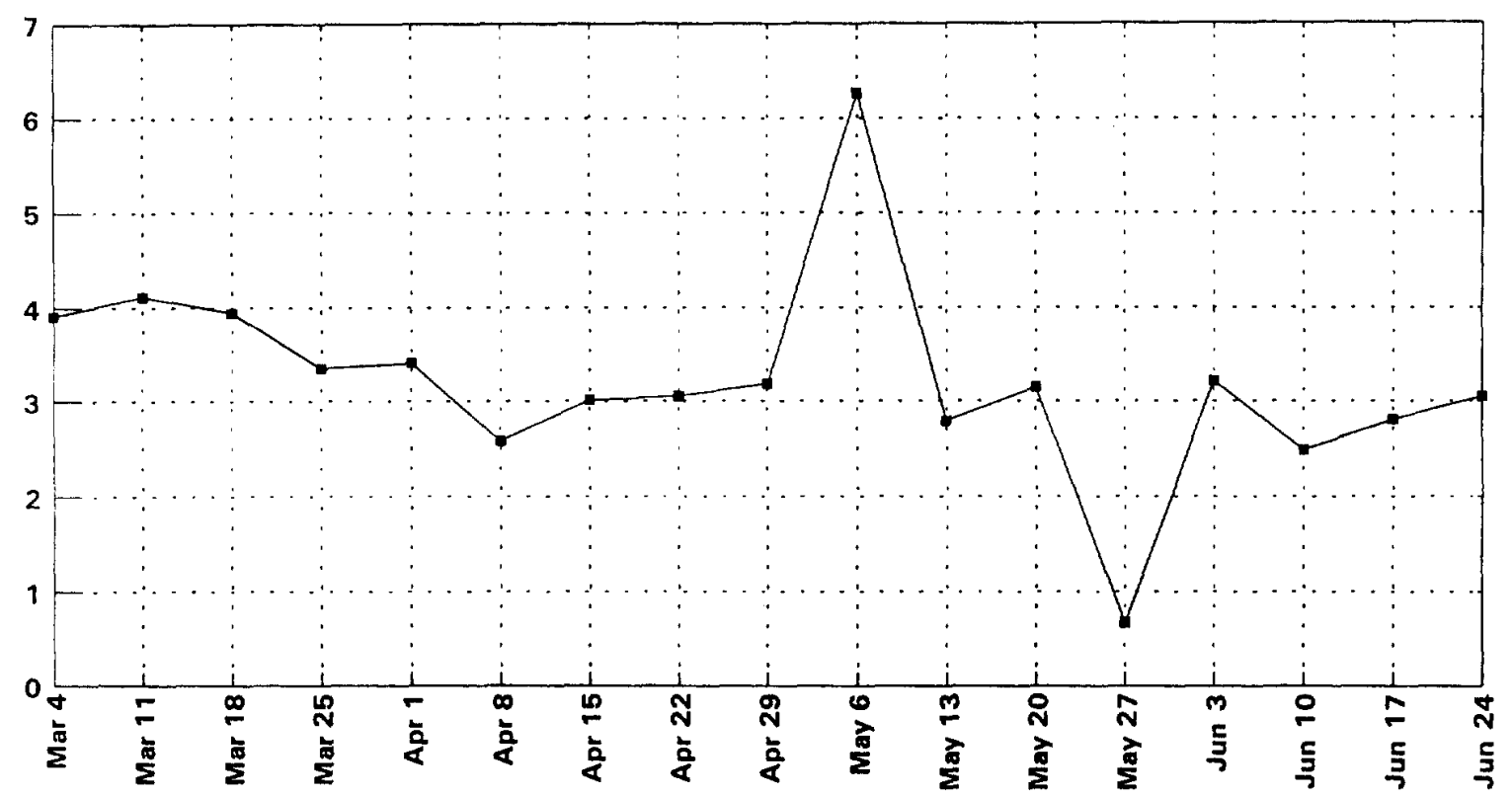

\section{- Series 1}

\section{(March 1, 1991 - June 26, 1991)}

Fig. 2. Time plot of Monday's call volumes, Area code 201.

used for the identification process. These 49 observations were utilized to predict observations at times 57 through 63 (April 26, 1991 through May 2, 1991). In essence, the first seven weeks of time series data was used to generate forecasts for the ninth week. Eight additional weeks of data were added to the database, one week at a time, to generate successive forecasts week by week. The forecasted values started one week after the end of the observed values because employee schedules were posted prior to the beginning of a new week. Thus, eight weeks were forecasted and compared with the actual (observed) time series by each method employed in this study.

\section{Intervention analysis}

Outliers can be thought of as additive, innovation, level shift, and temporary change. An additive outlier is an event, which occurs at a particular time and affects only one observation in the time series. An innovation outlier is one occurring at a particular time and affects all the observations after that time period but not in the same amount. A level shift is an event that affects all observations after its occurrence in the same amount. Finally, a temporary change is an event that occurs at a particular time period and affect observation at that time period but in decreasing amounts thereafter.

The detection of outliers is based upon examination of the residual series. The SCA software utilized in this study performs tests to determine whether the outlier is of one of the types described above. If outliers are detected, they are estimated by multiple regression-intervention analysis methods. Last, if an outlier is found for the last observation in the series, it is treated as an innovation outlier.

The intervention analysis procedure of SCA use maximum likelihood methods until an optimal model structure is found and no more outliers exist. (A 


\section{Number of Calls}

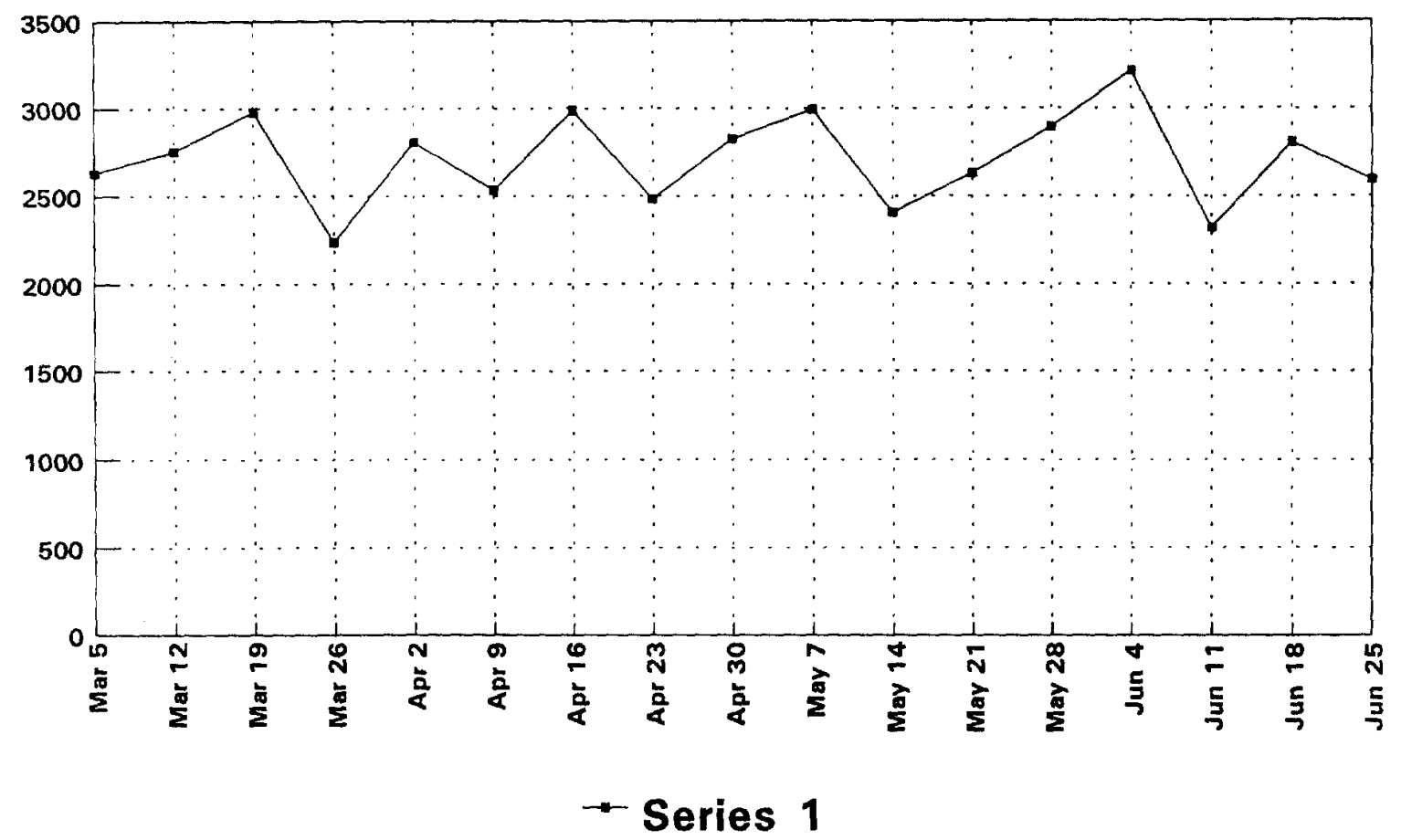

(March 1, 1991 - June 26, 1991)

Fig. 3. Time plot of Tuesday's call volumes, Area code 201.

more detailed examination of the intervention detection and analysis may be found in Chen and Liu, 1990, and Chen et al., 1991.)

\section{Results}

We elected to use the root mean square error (RMSE) as a measure of forecast performance. RMSE has been used in many previous studies (Brandon and Jarrett, 1979; Brandon et al., 1983, 1986; Jarrett, 1989, 1990).

Table 2, part (a), contains the RMSE of the forecasts in area code 201 for the three forecasting models utilized, i.e., ARIMA with intervention analysis, the multiplicative Holt-Winters model, and the additive Holt-Winters' model. Although we will examine each area code individually, the analysis will be summarized for the remaining five area codes sampled.
As one goes through Table 2 (and, also, the remaining tables containing ARIMA model specification) one will note certain continuities. The fitted models are for the most part simple models. As we add data to the model specification for each area code, the fitted models will change. However, the change is usually slight though no one model will be fitted for data sets both across and between the area codes. It is obvious the BJ model fitting is aided by the use of good computer software containing the appropriate diagnostics. Usually, the fitted ARIMA models are similar for data sets within a particular area code. This indicates is that for any data set, BJ model specification must be carried out and one cannot assume a particular function form for the time series under study. This conclusion is certainly in keeping with standard BJ analysis.

By studying the RMSE of all the forecasts, we can observe the relative accuracy of each of the methods used for each set of data under study. In Table 2 , 


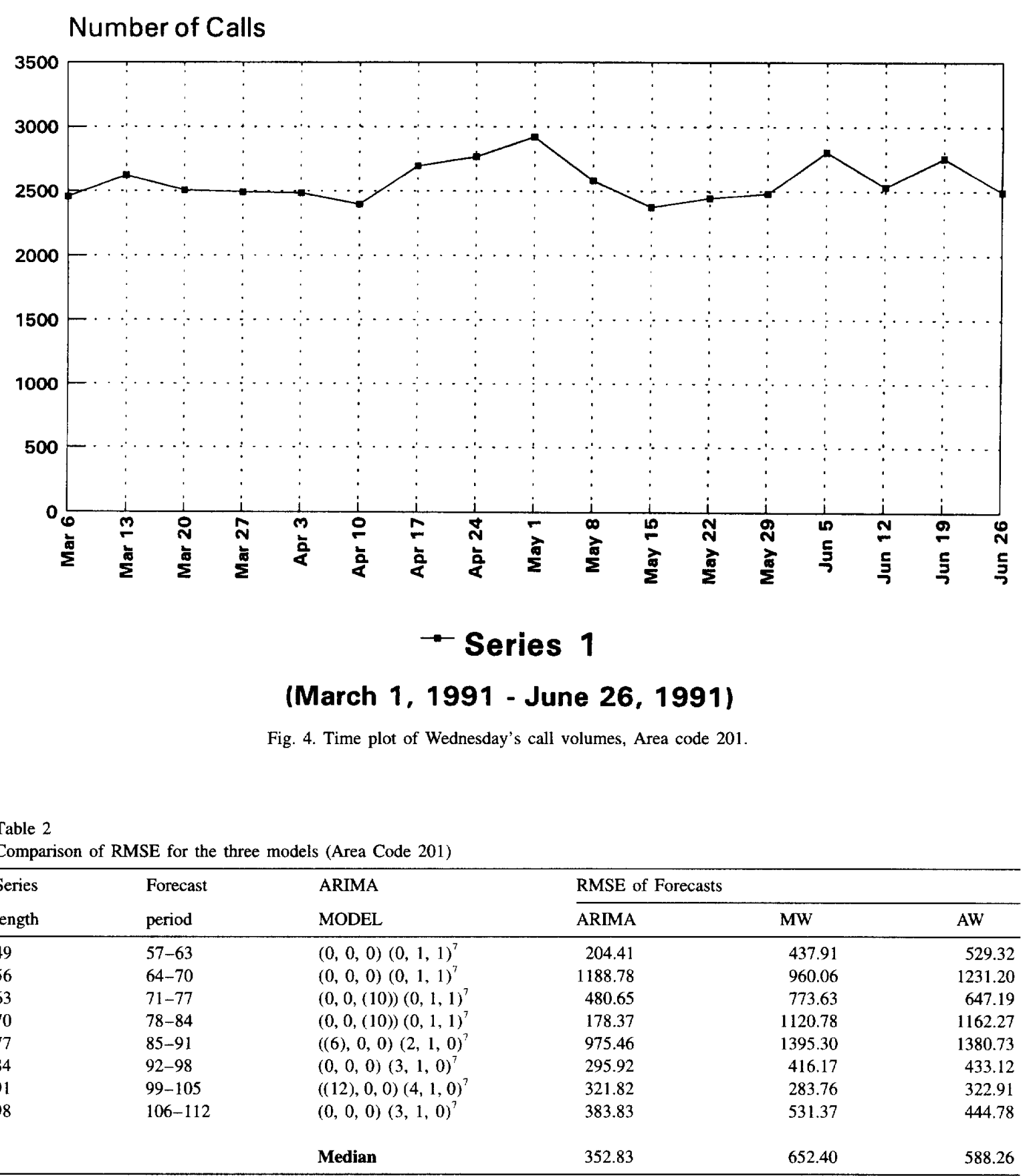

Note: $M W=$ Multiplicative Holt-Winters model, $A W=$ Additive Holt-Winters model. 
area code 201, the RMSE of the forecasts are smaller in the ARIMA models for 6 out of the 8 weeks studied. Note the median RMSE is also smaller for the ARIMA models

The tests for comparison should be on the performance measure, the RMSE, not upon individual errors. A simple sign test indicates that ARIMA is definitely better than AW. For example in Table 2 it is better on all eight sets. If ARIMA is compared to MW or to the best Holt-Winters model, it is better on six out of eight sets. The probability of this occurring due to chance (single tail test) is 0.035 . Although not shown here, this procedure was extended to all the series studied. The results indicated that ARIMA was better than the best of AW or MW in more than three-fourths of the sample outcomes.

Our results are relatively consistent across all the area codes sampled indicating that ARIMA/Intervention analysis is superior from the standpoint of forecast accuracy. A future study should consider whether the use of intervention analysis in ARIMA models would produce better-forecast results.

We also compared the medians of the errors for the sampled data (See Appendix A). The medians for the ARIMA/Intervention models were sufficiently smaller (or i.e. better) in comparison to either of the HW models. This indicates again that ARIMA/Intervention analysis is justified and that is economically sound; and shows the importance of analyzing outliers.

\section{Summary and conclusions}

The aim of this study include evaluating whether current methodology used by AT\&T is as good as ARIMA modeling with outlier detection. The method by which this evaluation was done calculated the RMSE for the forecasts and tested for differences in the methods.

The current methodology contained in the NAMES software, that is additive and multiplicative Holt-Winters' exponential smoothing models, may often perform adequately. Problems usually arise when outliers are present. ARIMA Models with outlier detection may provide a better method for forecasting for planning and control.
The conclusion of this study is limited to the time periods studied and for the time series data that were sampled. Future work in this area would be recommended for several reasons. Since the ARIMA methods were not always better, each time series studied must be examined individually to determine the appropriateness of the forecasting model. Series of longer length should be studied to determine whether outliers occur over prolonged time periods. If so, are ARIMA/Intervention Models comparable to methods designed to examine protracted time series such as fractional ARIMA models (FARIMA)?

\section{Appendix A}

Medians of RMSE of forecasts by area code and forecasting method

$\begin{array}{llll}\text { Area code } & \text { ARIMA } & \text { MW } & \text { AW } \\ 201 & 352.83 & 652.40 & 588.26 \\ 303 & 228.71 & 410.09 & 352.27 \\ 614 & 141.81 & 244.52 & 210.82 \\ 808 & 40.31 & 49.38 & 51.05 \\ 314 & 157.64 & 244.47 & 174.09 \\ 504 & 232.52 & 432.78 & 501.20\end{array}$

Note: ARIMA $=$ ARIMA/Intervention analysis method, $\mathrm{MW}=$ multiplicative winters method, $\mathrm{AW}=$ additive winters method.

\section{References}

Bowerman, B. L., \& O'Connell, R. T., (1993). Forecasting and Time Series: An Applied Approach. Duxbury Press, Belmont, CA.

Brandon, C., \& Jarrett, J., (1979). Revising earnings per share forecasts: an empirical test. Management Science, 25, 211220.

Brandon, C., Jarrett, J., \& Khumawala, S. B., (1983). Revising forecasts of accounting earnings: a comparison with the BoxJenkins method. Management Science, 29, 256-264.

Brandon, C., Jarrett, J., \& Khumawala, S. B., (1986). Comparing forecast accuracy for exponential smoothing models of earnings-per-share data for financial decision making. Decision Sciences, 17, 186-194. 
Chatfield, C., \& Yar, M., (1990). Prediction Intervals for the Holt-Winters forecasting Procedure. International Journal of Forecasting, 6, 127-138.

Chatfield, C., \& Yar, M., (1991). Prediction intervals for multiplicative Holt-Winters. Intemational Joumal of Forecasting, 7, 31-38.

Chen, C., \& Liu, L. M., (1990). Joint estimation of model parameters and outlier effects in time series. Working Paper Series, Scientific Computing Associates, P.O. 625, DeKalb, IL 60115.

Chen, C., Liu, L. M., \& Hudak, G.B., (1991). Outlier detection and adjustment in time series modeling and forecasting. Working Paper Series, Scientific Computing Associates, P.O. 625, Dekalb, IL 60115.

Grambsch, P., \& Stahel, W. A., (1990). Forecasting demand for special telephone services: a case study. International Journal of Forecasting, 6, 53-64.

Holt, C. C., (1957). Forecasting seasonals and trends by exponentially weighted moving averages. Carnegie Institute of Technology, Pittsburgh, PA.

Jarrett, J., (1989). Forecasting monthly earnings per share-time series models. OMEGA: International Journal of Management Science, $17(1), 37-44$.

Jarrett, J., (1990). Forecasting seasonal time series of corporate earnings: a note. Decision Sciences, 21, 888-894.

Jarrett, J., (1991). Business Forecasting Methods. Blackwell, Oxford.

Mahmoud, E., (1984). Accuracy in forecasting: a survey. Journal of Forecasting, 3, 139-159.

Makridakis, S., Andersen, A., Carbone, R., Fildes, R., Hibon, M., Lewandowski, R., Newton, J., Porzon, E., \& Winkler, R., (1982). The accuracy of extrapolative (time series) methods: The results of a forecasting competition. Journal of Forecasting, $1,111-153$

McKenzie, E., (1986). Error analysis for Winters' additive seasonal forecasting system. International Journal of Forecasting, 2, 373-382.

Pack, D., (1990). In Defense of ARIMA modeling. International Journal of Forecasting, 6, 211-218.

Thompson, P., (1981). Evaluation of the M-Competition forecasts via $\log$ mean squared error ratio. International Journal of Forecasting, 7, 331-334.
Winters, P. R., (1960). Forecasting sales by exponentially weighted moving averages. Management Science, 6, 324-342.

Biographies: Jeffrey JARRETT is Professor and former chairperson of the Department of Management Science at the University of Rhode Island. He was a recipient of a Ford Foundation Fellowship, and a Sears Foundation AACSB-Fellowship. He is the author of Business Forecasting Methods, (two editions); coauthor of Statistical Analysis for Decision Making; and author of Minitab: An Introductory Handbook. Dr. Jarrett has published numerous papers in The Accounting Review, Decision Sciences, Journal of Business Forecasting, Journal of Business Finance and Accounting, Journal of Accounting Research, Joumal of Finance, Journal of Risk and Insurance, Journal of Business and Economic Statistics, Management Science, OMEGA: The International Joumal of Management Science, Markets, and the Atlantic Economic Journal, among many others. He edited two special issues on Financial Forecasting for Managerial Finance (U.K.) Last, holds degrees from New York University and The University of Michigan. He was a student of Dr. W. Edwards Deming in both his masters and doctoral programs at New York University. He is a member of the Decision Sciences Institute, the American Statistical Association, and the International Institute of Forecasters.

R. Choudary HANUMARA is a Professor of Statistics at the University of Rhode Island. He received his Ph.D. in Statistics from Florida State University. His areas of research interests include Multivariate Methods, Sampling, Nonparametric Methods and applications of Statistics.

Lisa BIANCHI received her Master of Science in Statistics at the University of Rhode Island. She is currently pursuing a $\mathrm{Ph} . \mathrm{D}$. at Tufts University. Her interests include Forecasting and applications of Statistics in Health. 